\title{
Update on transfusion solutions during surgery: review of hydroxyethyl starches I30/0.4
}

This article was published in the following Dove Press journal:

International Journal of General Medicine

25 September 2010

Number of times this article has been viewed

\section{Ornella Piazza \\ Giuliana Scarpati \\ Rosalba Tufano}

Anaesthesia and Intensive Care, University of Naples Federico II, School of Medicine, Naples, Italy
Correspondence: Dr Ornella Piazza University of Naples Federico II, School of Medicine,Via Pansini 5, 80I3I Naples, Italy Email orpiazza@unina.it:
Objectives: Restoration of circulation is crucial in the surgical patient management. Colloids and crystalloids are widely used for blood volume therapy. We reviewed recent trials to evaluate efficacy and safety of hydroxyethyl starch (HES) 130/0.4 during surgery.

Material and methods: A subjective, not systematic, review of literature was performed. Papers were searched to answer questions about efficacy of HES, its impact on coagulation and inflammation and its effects on pulmonary mechanics and renal function.

Conclusions: HES 130/0.4 is effective for volume therapy and is less expensive than human albumin. Its effects on coagulation and renal function are manageable; it may ameliorate pulmonary permeability and reduce inflammation.

Keywords: HES, colloids, volume loading, coagulation, inflammation, surgery, renal function, pulmonary mechanics

Hydroxyethyl starch (HES) solutions are synthetic colloids used to correct hypovolemia. HES contains glycogen-like modified natural polysaccharides ${ }^{1,2}$ and can be classified according to their molecular weight (MW), concentration, and degree of substitution. Hydroxyethyl starch 130/0.4 (mean molecular weight, $130 \mathrm{kd}$; degree of substitution, 0.4 ) is a relatively new medium-molecular-weight HES solution. The development of newer starch-based plasma volume expanders has been driven by the need to improve safety and pharmacological properties while maintaining the volume efficacy of previous HES generations. Reductions in MW and molar substitution (MS) have led to products with shorter half-lives, improved pharmacokinetic and pharmacodynamic properties, and fewer side effects. ${ }^{3}$ Earlier products were all derived from amylopectin extracted from waxy maize starch but it is inaccurate to refer to HES as if they were only one homogenous product because modifications to MW and the degree and pattern of substitution result in distinct and observable differences between and within the different generations of HES.

The same is true for starches of similar structure that have been derived from different source materials: waxy maize and potato. Two third-generation starches based on these two materials are currently available in various formulations. According to the results of one study, potato and waxy maize-derived HES solutions are not bioequivalent. ${ }^{4}$ Therefore, findings obtained from studies using one type may not be valid for the other.

Early experimental studies produced reports of increased mortality rates in mice that received HES solutions before an endotoxin challenge and in a rat endotoxin model, HES 10\% (200/0.5) was less effective than albumin in preventing 
lipopolysaccharide-induced myocardial dysfunction ${ }^{5}$. There is continuing concern regarding possible adverse effects of HES solutions including coagulopathy, anaphylactoid reactions, and renal impairment.

It has been suggested that the modern generation HES solutions, 6\% HES (130/0.4), may be less likely to induce nephrotoxicity and may impair blood coagulation less than other HES solutions and thus, may be used in larger doses without increasing the risk of postoperative bleeding.

In this paper we review some of the relevant articles regarding the use of HES 130/0.4 during surgery, looking for answers to five of the most asked questions on this subject.

\section{Is HES I30/0.4 more efficient in plasma substitution than other colloids?}

A recent systematic review of randomized clinical studies on the use of fluid therapy in various types of surgical procedures found no evidence to recommend one type of fluid therapy over another. There was not sufficient evidence to provide guidance on the optimal amount of fluid to use in elective surgical procedures. ${ }^{6}$ It was therefore concluded that guidelines for perioperative fluid management must be procedure-specific; in the absence of firm evidence for one approach or another, individualized, goal-directed fluid administration should be used. Currently, it appears that a restrictive rather than a liberal fluid regimen is beneficial in patients undergoing colorectal surgery. Conversely, patients suffering from systemic inflammation appear to benefit from aggressive fluid replacement, as demonstrated by Rivers et al. ${ }^{7}$ This is in line with the conclusion of Brandstrup, who critically evaluated the evidence behind current standard fluid therapy and the effect of fluid therapy on the outcomes of surgery. ${ }^{8}$ The latter author reported that choice of standard fluid therapy is not generally evidence-based and that methodological flaws during attempts to restrict fluid therapy actually result not in restriction but simply replacement of lost fluids. Therefore, it is recommended to replace lost fluid and avoid fluid overload, which echoes earlier recommendations to adopt goal-directed intraoperative fluid therapy. ${ }^{9}$

Despite the absence of clear recommendations for any particular fluid therapy, there is plentiful debate about the relative merits of crystalloid or colloid, and even about different types of colloids. As recently remarked by Boldt in an editorial, "Researchers who show crystalloid to be superior always find crystalloid superior, whereas colloid supporters always favor colloids". ${ }^{10}$
Adequate restoration of intravascular volume remains the crucial therapeutic maneuver in managing the surgical patient. It is generally believed that three to four times more crystalloid than colloid volume is needed to achieve an equivalent plasma volume expansion. However, in the SAFE trial, ${ }^{11}$ in which fluid administration was blinded, the ratio of albumin to saline was 1:1.4 and thus much less than expected. While the choice between colloid and crystalloid solutions continues to generate controversy, the dispute has been enlarged to a colloid/colloid debate (eg, dextrans, gelatins, HES solutions).

Vanhoonacker et $\mathrm{al}^{12}$ studied 157 electively scheduled patients randomly allocated to $6 \% \operatorname{HES}(n=85)$ or gelatine $(\mathrm{n}=72)$ CPB (cardiopulmonary bypass) priming. According to their data, HES $130 / 0.4$ is a safe alternative to gelatine pump prime with a volume effect persisting longer in the postoperative phase, mandating less volume expansion with artificial colloid during the first 24 postoperative hours. Albumin supplements occurred more frequently in the HES group between 2 and 3 hours postoperatively but total artificial colloid supplement was significantly higher in the gelatin group (13.36 versus $8.96 \mathrm{~mL} / \mathrm{kg}, P<0.001)$. There were no differences in the number of packed red cells, fresh frozen plasma, or platelets transfused between the two groups.

Hanart et $\mathrm{al}^{13}$ compared $4 \%$ albumin with $6 \%$ HES 130/0.4 in 190 children undergoing cardiac surgery, randomized to receive either $4 \%$ albumin $(n=59)$ or $6 \%$ HES $130 / 0.4(n=60)$ for intraoperative fluid volume replacement including the cardiopulmonary bypass priming fluid. Volume of colloid used intraoperatively was similar in both groups.

They concluded that in children undergoing cardiac surgery, $6 \%$ HES 130/0.4 may represent an alternative to $4 \%$ albumin for intraoperative fluid volume replacement because of its lower cost.

\section{Is blood loss and risk of bleeding increased with HES I30/0.4 during surgery?}

The in vitro and in vivo effects of various HES products on coagulation and platelet function have been investigated in a number of studies. Overall, the more rapidly degradable HES products have been found to have a greatly reduced effect on the coagulation process compared to older products. ${ }^{14,15}$

HES macromolecules interact with platelets and the coagulation cascade, causing a decrease in factors such as Factor VIII and von Willebrand factor but the exact mechanisms have still not been fully elucidated. ${ }^{16}$ There have been consistent reports of coagulation impairment since slowly 
degradable HES preparations were introduced into clinical practice. These HES preparations decreased circulating plasma concentrations of coagulation factors in volunteers and patients, even when used below the recommended maximum doses..$^{15,17-22}$

It is recommended that the maximum doses of HES not exceed 20 and $33 \mathrm{~mL} / \mathrm{kg}$ per day for high- and mediummolecular-weight HES solutions, respectively.

Treib et al carried out systematic studies of the effects of a range of HES preparations and found that the products with higher MS had a profound effect on coagulation and platelet function but suggested that newer HES preparations should only have minimal effects. ${ }^{23,24}$ Results of in vitro studies of the coagulation process indicate that the altered pharmacokinetics of the newer generation of HES preparations have led to products with moderate effects on coagulation and platelet function. ${ }^{18,25-27}$ However, in vitro studies have limitations and may be misleading since, in the absence of the normal compensatory mechanisms, at least part of the observed effects may be attributable to simple hemodilution or to the presence of calcium in the solvents. ${ }^{28,29}$ The biochemical mechanisms causing dilutional coagulopathy following infusion of hydroxyethyl starch 130/0.4 have been recently studied by Fenger-Eriksen et $\mathrm{al}^{30}$ acquired fibrinogen deficiency constitutes the most important determinant of the coagulopathy.

A total of 20 bleeding patients were examined; ${ }^{30}$ blood loss was substituted with HES up to a target level of $30 \%$ and thromboelastometry, platelet count, thrombin generation, and the activities of von Willebrand factor, coagulation factor II, FVII, FVIII, FIX, FX, and FXIII were measured. All coagulation factor activities were reduced. Ex vivo addition of fibrinogen corrected the coagulopathy completely.

The most useful evidence concerning the safety of waxy maize-derived 6\% HES 130/0.4 is derived from extensive clinical studies in many types of major surgery. Although very high doses have been used, ${ }^{31}$ no adverse effects on coagulation have been reported compared to controls using lower doses.

In one high-dose study, Ellger et $\mathrm{al}^{32}$ found that $6 \% \mathrm{HES}$ $130 / 0.4$, when given in doses up to $50 \mathrm{~mL} / \mathrm{kg}$, had similar effects on coagulation as $30 \mathrm{~mL} / \mathrm{kg}$ HES 200/0.5 plus gelatin. In this study, 40 patients undergoing elective surgery for urology-related cancer were randomized to receive one of the HES preparations. Coagulation parameters were measured at five time points during and after surgery. The authors noted that there was some deterioration of coagulation during surgery but that this was most likely the result of blood loss and hemodilution. No significant differences were found between groups in terms of hemoglobin, hematocrit, platelet count, coagulation factors (prothrombin time, partial thromboplastin time, von Willebrand factor, Factor VIIIc), or blood loss. Similar results were obtained in a study of 120 patients undergoing elective coronary artery bypass surgery. ${ }^{33}$ Patients were randomized to volume replacement either with $6 \%$ HES 130/0.4 (up to $50 \mathrm{~mL} / \mathrm{kg}$ ) or $6 \%$ HES 200/0.5 (up to $33 \mathrm{~mL} / \mathrm{kg}$ ) with volume requirements in excess of these doses being met with gelatin. Despite being used at a median dose of $49 \mathrm{~mL} / \mathrm{kg}$, HES 130/0.4 did not increase blood loss and transfusion requirements compared to the lower dose of HES 200/0.5. The authors also noted that patients randomized to be treated with pentastarch received three times as much gelatin as those in the tetrastarch group and speculated that this should, if anything, have biased this group towards reduced blood loss.

\section{Safety of HES I 30/0.4 in patients with renal dysfunction: comparison with other colloids}

Concerns about the possible deleterious effects of HES on renal function were first raised by Legendre et al in a retrospective study investigating the association between HES exposure of organ donors and the subsequent tissue storage in the recipients. ${ }^{34}$ Cittanova et $\mathrm{al}^{35}$ later found a link between the use of HES 200/0.62 in kidney donors and the subsequent need for hemodialysis in the recipients, but Deman et al could not confirm these results in their retrospective analysis. ${ }^{36}$ The authors suggested that the nephrotoxicity noted by Legendre et $\mathrm{al}^{34}$ might have resulted from the use of a particular preservation agent. Other researchers also failed to find any deterioration in renal function associated with the use of various HES preparations: 6\% HES 200/0.5 and HES 70/0.5, ${ }^{37}$ $6 \%$ HES 200/0.5, 6\% HES 200/0.62, and 6\% HES 450/0.7, ${ }^{38}$ even when high doses were used. ${ }^{31}$ In a randomized study of elderly patients undergoing cardiopulmonary bypass surgery, Boldt et al found no difference in the levels of kidney-specific proteins between patients who received 6\% HES 130/0.4 and those who received gelatin. ${ }^{39}$ In another randomized study with similar patients, comparing the same HES agent with $5 \%$ albumin, Boldt et al again found no difference in renal function between the two groups. ${ }^{40}$ In the considerable body of clinical data on the third-generation HES 130/0.4, there have been no reports of adverse effects on renal function over and above those seen in control groups, in patients who are considered to be at particular risk, such as those with previous mild to severe renal dysfunction, ${ }^{41-43}$ the elderly, ${ }^{44}$ 
and those receiving high-dose therapy. ${ }^{31}$ Fenger-Eriksen et $\mathrm{al}^{44}$ performed studies in the area and found that a colloid-based fluid regime (6\% HES 130/0.4) may preserve renal function to a greater extent than crystalloids in patients undergoing spinal surgery. Similarly, Godet et $\mathrm{al}^{45}$ suggested that $6 \%$ HES 130/0.4 was as safe as gelatin (Plasmion ${ }^{\circledR}$; Fresenius France Pharma, Sevres, France) in patients with prior renal dysfunction undergoing abdominal aortic surgery. Although baseline renal function was impaired in all patients (creatinine clearance $[\mathrm{CrCl}]$ less than $80 \mathrm{~mL} / \mathrm{min}$ ), no drug-related unfavorable effects on renal function were found using HES $130 / 0.4$ compared to gelatin.

One of the criticisms directed against many earlier studies, is that the follow-up periods have been relatively short. ${ }^{43}$ Fifty patients undergoing cardiac surgery were randomized to either $6 \%$ HES $130 / 0.4$ or $5 \%$ human albumin given perioperatively until the second postoperative day. At a 60-day follow up, it was found that kidney function in patients receiving tetrastarch was as preserved as with albumin. Although concentrations of kidney-specific proteins increased after surgery in both groups, there was no difference between groups. None of the patients developed acute renal failure leading to renal replacement therapy, either during hospital stay or in the follow-up period.

Three recently published studies confirm these findings. In a randomized study of 50 patients assigned to either a balanced regimen (6\% HES 130/0.42 plus crystalloid solution) or a saline-based regimen (saline plus MS of the HES) kidney integrity was less altered with the HES 130/0.42. Levels of glutathione transferase alpha and neutrophil gelatinase-associated lipocalin were raised in both groups, but less so in the group with the plasma-adapted solutions. ${ }^{46}$

Another recent publication contains preliminary results of an observational study of pediatric patients aged up to 12 years undergoing various types of surgery while receiving $6 \%$ HES $130 / 0.42$. This noncomparative study evaluated the perioperative use of HES 130/0.42 in 1,000 children, with a particular focus on cardiovascular stability, hemodilution, acid-base balance, renal function, blood coagulation, and hypersensitivity. Reports on the first 300 children have shown no serious effects on renal function. ${ }^{47}$

It has been suggested from perioperative studies in low-risk patients who received cumulative doses in the range of only $50 \mathrm{~mL} / \mathrm{kg}$ body weight, that HES 130/0.4 may be less likely to induce nephrotoxicity than HES 10\%.

In surgical ICU patients, the incidence of ARF was similar in patients who received predominantly HES 130/0.4 fluid therapy and in those who received predominantly gelatin $4 \%{ }^{48,49}$ In summary, the published data on this topic suggest that there are differences between the older and newer generations of HES and that the reports of adverse effects on renal function should not be extrapolated to newer HES products. Moreover the Cochrane Collaboration Review [Dart AB, Mutter TC, Ruth CA, Taback SP, Hydroxyethyl Starch (HES) versus other fluid therapies: effects on kidney function. Database of Systematic Reviews 2010, Issue 1] concluded that "there is inadequate clinical data to address the claim that safety differences exist between different HES products".

\section{Pulmonary mechanics: comparison of HES I30/0.4 and other fluids}

Crystalloids may promote fluid extravasation in the lungs and formation of pulmonary edema since they tend to lower colloid osmotic pressure (COP). In contrast, colloids may decrease pulmonary fluid extravasation and the formation of pulmonary edema because of their capacity to increase COP. The so-called colloid-crystalloid controversy includes the relative propensity of fluid types to evoke pulmonary edema, which is not yet settled in the absence of direct permeability and edema measurements in most studies. ${ }^{50}$ Indeed, the controversy is complicated by the fact that the potentially protective role of COP may diminish when permeability is increased, while the propensity for edema formation may increase, unless hydrostatic pressure is kept low, as demonstrated in experimental and human studies. ${ }^{51-53}$

Cardiac and major vascular surgery are often complicated by hypovolemic hypotension, necessitating fluid therapy, but the optimal type of fluid for this purpose is hotly debated. ${ }^{50,54-61}$ Cardiac and major vascular surgery, involving ischemia and reperfusion, are well known risk factors for a systemic inflammatory response and for acute lung injury/acute respiratory distress syndrome (ALI/ARDS), associated with increased capillary permeability in the lungs in some patients, as measured by a noninvasive double radionuclide technique to detect pulmonary Ga-transferrin extravasation. ${ }^{62-66}$ This could thus affect the contribution of infusion fluids to pulmonary edema formation. Indeed, researchers have documented an increase in extravascular lung water (EVLW) after cardiac or major vascular surgery and fluid loading, at least transiently in some patients. ${ }^{57-59,67-70}$ Verheij et $\mathrm{al}^{71}$ hypothesized that colloid fluid loading would aggravate less edema formation in the lungs than saline loading in the treatment of presumed hypovolemia after major surgery, even if complicated by increased pulmonary permeability. They also hypothesized 
that hydroxyethyl starch (HES) or albumin loading would attenuate pulmonary edema attributable to increased permeability as compared with gelatin loading. They therefore compared filling pressure-guided fluid challenges ${ }^{72}$ with saline and with the colloids gelatin, HES, and albumin on their effects on pulmonary capillary permeability, EVLW, COP, and the lung injury score (LIS) in 67 presumably hypovolemic patients after cardiac or major vascular surgery. In this study more saline was infused than colloid solutions $(P<0.005)$. The COP increased in the colloid groups and decreased in patients receiving saline. Cardiac output increased more in the colloid groups. At baseline, pulmonary leak index (PLI) and EVLW were above normal in $60 \%$ and $30 \%$ of the patients, with no changes after fluid loading, except for a greater PLI decrease in HES than in gelatin-loaded patients. The oxygenation ratio was improved in all groups. In the colloid groups, the LIS was increased because of a decrease in total respiratory compliance, probably associated with an increase in intrathoracic plasma volume. It was concluded that saline or colloids do not affect permeability edema in ALI after cardiac or major vascular surgery, provided that fluid overloading is avoided, and except for HES which may ameliorate increased permeability. The LIS, however, may slightly increase after colloid versus saline loading, because of greater intrathoracic plasma volume expansion decreasing total respiratory compliance, thus indicating that changes in LIS (and respiratory compliance) during fluid loading do not represent only changes in permeability edema.

\section{Does HES I 30/0.4 reduce inflammatory response to surgery?}

As with all forms of trauma, surgery triggers a systemic inflammatory response with the release of inflammatory mediators into the systemic circulation. Proinflammatory cytokines, such as interleukin-6 (IL-6) and IL-8, play an important role in regulating the acute inflammatory phase. Cell adhesion molecules, such as E-selectin, endothelial leukocyte adhesion molecule-1 (ELAM-1), and intercellular adhesion molecule-1 (ICAM-1) regulate the interaction away immune cells with the endothelium and the extracellular matrix. It has been demonstrated that release of IL-6 correlates with the severity of surgery. ${ }^{72}$ In particular, surgery of the intestine is associated with a greater inflammatory response than other types of surgery, ${ }^{73}$ and the elderly population may also show an enhanced inflammatory response. ${ }^{74,75}$ It is, therefore, of interest to assess the effects of volume replacement solutions on the mediators of inflammation.
In a study of patients undergoing abdominal surgery, Lang et $\mathrm{al}^{76}$ found a significantly lower increase of the proinflammatory cytokines IL-6 and IL-8 in patients receiving 6\% HES 130/0.4 compared to those receiving lactated Ringer's solution. There were also significantly lower serum concentrations of soluble ICAM-1 (sICAM-1) in the HES group.

Likewise, in patients undergoing major abdominal surgery, Boldt et $\mathrm{al}^{77}$ reported a similar attenuation of plasma levels of IL-6 in patients receiving 6\% HES 130/0.4 compared to those receiving 5\% albumin. Plasma levels of endothelial adhesion molecules (sELAM-1, sICAM-1) were also significantly lower in the HES group, returning to normal on the day after surgery and remaining elevated in patients receiving albumin. In a study of elderly patients undergoing cardiac surgery, inflammatory response was similar in groups receiving 5\% albumin and those receiving 6\% HES 130/0.4, whereas endothelial activation was lower in the HES group. ${ }^{40}$ Boldt speculates that the beneficial effect of HES 130/0.4 on inflammation and endothelial activation may be the result of some direct, substance-specific effects on endothelial cells resulting in reduced release of adhesion molecules. ${ }^{77}$ Using endothelial cell cultures, Collis et $\mathrm{al}^{78}$ found that lipopolysaccharide-stimulated expression of adhesion ligand P-selectin was inhibited by HES.

Volta et $\mathrm{al}^{79}$ reported that HES $130 / 0.4$ was able to selectively inhibit the activity of matrix metalloproteinase- 9 (MMP-9) in vitro compared to lactated Ringer's solution. This was confirmed in 36 patients scheduled for colon cancer surgery who were randomized to $6 \%$ HES 130/0.4, 3.4\% polygeline or lactated Ringer's solution. After surgery, plasma levels of MMP-9 and tissue inhibitor of MMP-9 (TIMP-9) were higher in all three groups, but they were significantly lower in the tetrastarch group than in the other two groups.

In a number of in vitro and animal studies light has been shed on the possible mechanisms by which HES might affect the inflammatory process. Using cultured human microvascular endothelial cells and mice, Dieterich et $\mathrm{al}^{80}$ found that physiologically relevant concentrations of tetrastarch were able to reduce neutrophil adhesion in vitro, while vascular leakage and pulmonary edema induced by hypoxia exposure were reduced in animals treated with HES. Nohé et al ${ }^{81}$ studied the expression of adhesion molecules on native and cytokineactivated endothelium from umbilical veins after pretreatment with gelatin and various preparations of dextran and HES. The authors concluded that synthetic colloids inhibit neutrophil adhesion by a neutrophil-dependent mechanism rather than interfering with endothelial cell activation. 


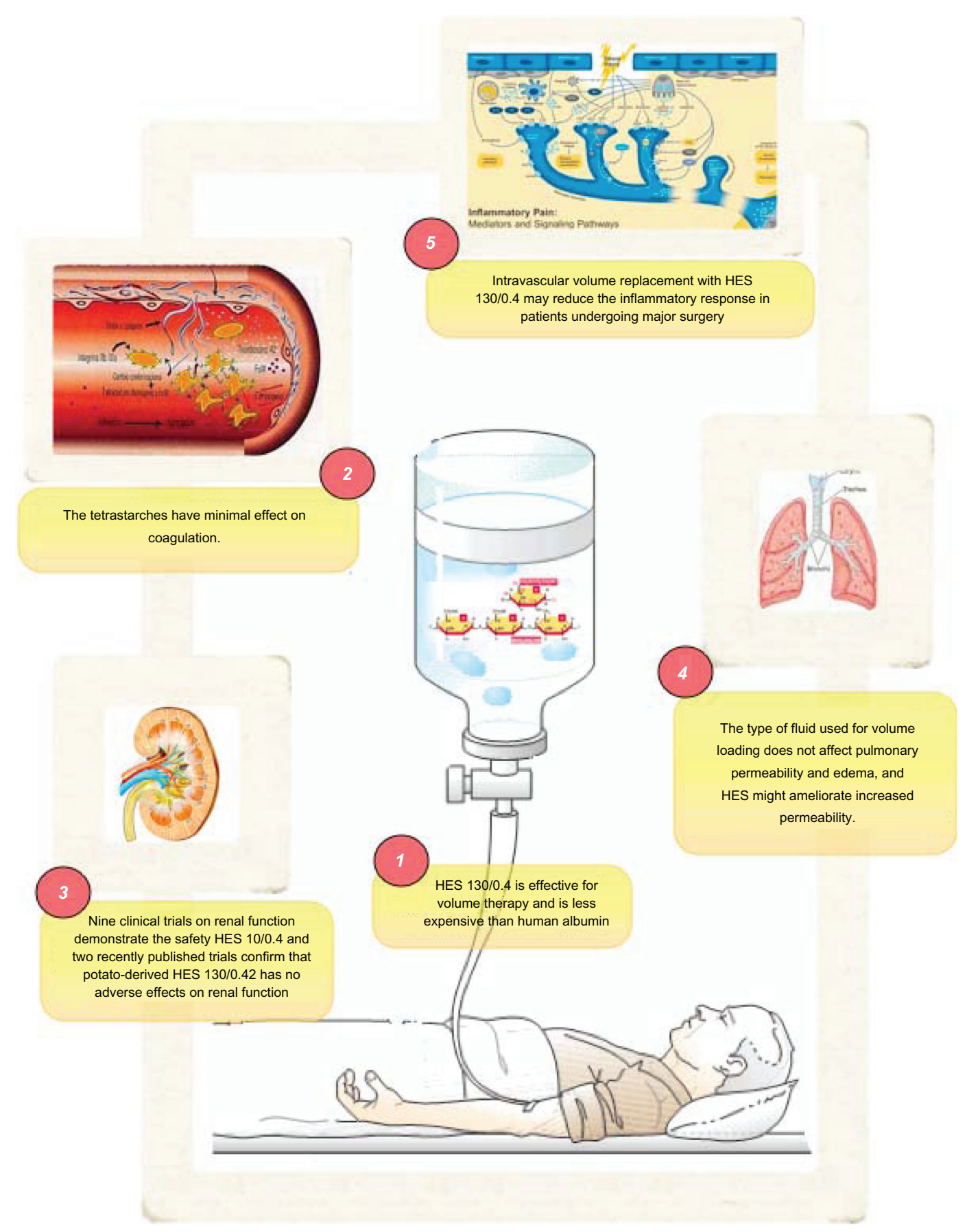

Figure I Results for each of the five questions investigated in the present study.

\section{Conclusion}

The evidence base for HES 130/0.4 is strong; overall, there are more than 50 published studies reporting on the coagulation effects of waxy maize-derived HES 130/0.4, including more than 20 Phase II to IV studies. These studies confirm that, unlike earlier generation HES preparations, the tetrastarches have minimal effects on coagulation.

Results of nine clinical trials on renal function support the safety of HES 130/0.4, and two recently published trials confirm that potato-derived HES 130/0.42 has no adverse effects on renal function, but there are inadequate clinical data to address the claim that safety differences exist between different HES products. Intravascular volume replacement with HES 130/0.4 may reduce the inflammatory response in patients undergoing major surgery compared to a crystalloidbased volume therapy. Finally, the type of fluid used for volume loading does not affect pulmonary permeability and edema, and HES may ameliorate increased permeability (Figure 1). 


\section{Disclosure}

The authors report no conflicts of interest.

\section{References}

1. Treib J, Baron JF, Grauer MT, Strauss RG. An international view of hydroxyethyl starches. Intensive Care Med. 1999;25:258-268.

2. Brunkharst FM, Engel C, Bloss F, Meier-Hellmann A, Ragaller M, Weiler $\mathrm{N}$, et al. Intensive Insuline therapy and pentasterch resuscitation in severe sepsis. N Engl J Med. 2008;358:125-139.

3. Sommermeyer K, Cech F, Schossow R. Differences in chemical structures between waxy maize- and potato-starch-based hydroxyethyl starch volume therapeutics. Transfus Altern Transfus Med. 2007;9 127-133.

4. Lehmann G, Marx G, Förster H. Bioequivalence comparison between hydroxyethyl starch 130/0.42/6:1 and hydroxyethyl starch 130/0.4/9:1. Drugs RD. 2007;8:229-240.

5. Walley KR, McDonald TE, Wang Y, Dai S, Russell JA. Albumin resuscitation increases cardiomyocyte contractility and decreases nitric oxide synthase II expression in rat endotoxemia. Crit Care Med. 2003 31:187-194.

6. Holte K, Kehlet H. Fluid therapy and surgical outcomes in elective surgery: A need for reassessment in fast-track surgery. J Am Coll Surg. 2006;202:971-989

7. Rivers E, Nguyen B, Havstad S, et al. Early goal-directed therapy in the treatment of severe sepsis and septic shock. $N$ Engl J Med. 2001; 345:1368-1377.

8. Brandstrup B. Fluid therapy for the surgical patient. Best Pract Res Clin Anaesthesiol. 2006;20:265-283.

9. Gan TJ, Soppitt A, Maroof M, et al. Goal-directed intraoperative fluid administration reduces length of hospital stay after major surgery. Anesthesiology. 2002;97:820-826.

10. Boldt J. Pro use of colloids in cardiac surgery. $J$ Cardiothorac Vasc Anesth. 2007;21:453-456.

11. Finfer S, Bellomo R, Boyce N, French J, Myburgh J, Norton R A comparison of albumin and saline for fluid resuscitation in the intensive care unit. $N$ Engl J Med. 2004;350:2247-2256.

12. Vanhoonacker J, Ongenae M, Vanoverschelde H, Donadoni R Hydroxyethyl starch 130/0.4 versus modified fluid gelatin for cardiopulmonary bypass priming: the effects on postoperative bleeding and volume expansion needs after elective CABG. Acta Anaesthesiol Belg. 2009;60(2):91-97.

13. Hanart C, Khalife M, De Villé A, Otte F, De Hert S, Van der Linden P. Perioperative volume replacement in children undergoing cardiac surgery: albumin versus hydroxyethyl starch 130/0.4. Crit Care Med. 2009;37(2):696-701.

14. MacIntyre E, Mackie IJ, Ho D, Tinker J, Bullen C, Machin SJ. The haemostatic effects of hydroxyethyl starch (HES) used as a volume expander. Intensive Care Med. 1985;11:300-303.

15. Claes Y, van Hemelrijck J, van Gerven M, et al. Influence of hydroxyethyl starch on coagulation in patients during the perioperative period. Anesth Analg. 1992;75:24-30

16. Kozek-Langenecker S. Effects of hydroxyethyl starch solutions on hemostasis. Anesthesiology. 2005;103:654-660

17. Gandhi SD, Weiskopf RB, Jungheinrich C, et al. Volume replacement therapy during major orthopaedic surgery using Voluven (hydroxyethyl starch 130/0.4) or hetastarch. Anesthesiology. 2007;106:1120-1127.

18. De Jonge E, Levi M, Büller HR, Berends F, Kasecioglu J. Decreased circulating levels of von Willebrand factor after intravenous administration of a rapidly degradable hydroxyethyl starch (HES 200/0.5/6) in healthy human subjects. Intensive Care Med. 2001;27:1825-1829.

19. Jamnicki M, Bombeli T, Seifert B, et al. Low- and mediummolecular-weight hydroxyethyl starches: Comparison of their effect on blood coagulation. Anesthesiology. 2000;92:1231-1237.

20. Kapiotis S, Quehenberger P, Eichler H, et al. Effect of hydroxyethyl starch on the activity of blood coagulation and fibrinolysis in healthy volunteers: comparison with albumin. Crit Care Med. 1994;22: 606-612.
21. Jones SB, Whitten CW, Despotis GJ, Monk TG. The influence of crystalloid and colloid replacement solutions in acute normovolemic hemodilution: a preliminary survey of hemostatic markers. Anesth Analg. 2003;96:363-368.

22. Conroy JM, Fishman RL, Reeves ST, Pinsoky ML, Lazarchick J. The effects of desmopressin and 6\% hydroxyethyl starch on factor VIIIC. Anesth Analg. 1996;83:804-807.

23. Treib J, Haass A, Pindur G, et al. HES 200/0.5 is not HES 200/0.5. Influence of the $\mathrm{C} 2 / \mathrm{C} 6$ hydroxyethylation ratio of hydroxyethyl starch (HES) on hemorheology, coagulation and elimination kinetics. Thromb Haemost. 1995;74:1452-1456.

24. Treib J, Haass A, Pindur G, Treib W, Wenzel E, Schimrigk K. Influence of intravascular molecular weight of hydroxyethyl starch on platelets. Eur J Haematol. 1996;56:168-172.

25. Franz A, Bräunlich P, Gamsjäger T, et al. The effects of hydroxyethyl starches of varying molecular weights on platelet function. Anesth Analg. 2001;92:1402-1407.

26. Entholzner EK, Mielke LL, Calatzis AN, Feyh J, Hipp R, Hargasser SR. Coagulation effects of a recently developed hydroxyethyl starch (HES 130/0.4) compared to hydroxyethyl starches with higher molecular weight. Acta Anaesthesiol Scand. 2000;44:1116-1121.

27. Konrad CJ, Markl TJ, Schuepfer GK, Schmeck J, Gerber HR. In vitro effects of different medium molecular hydroxyethyl starch solutions and lactated Ringer's solution on coagulation using SONOCLOT. Anesth Analg. 2000;90:274-279.

28. Jamnicki M, Zollinger A, Seifert B, Popovic D, Pasch T, Spahn DR. Compromised blood coagulation: an in vitro comparison of hydroxyethyl starch 130/0.4 and hydroxyethyl starch 200/0.5 using thromboelastography. Anesth Analg. 1998;87:989-993.

29. Deusch E, Thaler U, Kozek-Langenecker SA. The effects of high molecular weight hydroxyethyl starch solutions on platelets. Anesth Analg. 2004;99:665-668.

30. Fenger-Eriksen C, Tønnesen E, Ingerslev J, Sørensen B. Mechanisms of hydroxyethyl starch-induced dilutional coagulopathy. J Thromb Haemost. 2009;7(7):1099-1105.

31. Neff TA, Doelberg M, Jungheinrich C, Sauerland A, Spahn DR, Stocker R. Repetitive large-dose infusion of the novel hydroxyethyl starch 130/0.4 in patients with severe head injury. Anesth Analg. 2003; 96:1453-1459.

32. Ellger B, Freyhoff J, Van Aken H, Booke M, Markus MA. High dose volume replacement using HES 130/0.4 during major surgery. Impact on coagulation and incidence of postoperative itching. Neth Tijdschr Anesth. 2006;19:63-68.

33. Kasper SM, Meinert P, Kampe S, et al. Large-dose hydroxyethyl starch 130/0.4 does not increase blood loss and transfusion requirements in coronary artery bypass surgery compared with hydroxyethyl starch 200/0.5 at recommended doses. Anesthesiology. 2003;99:42-47.

34. Legendre C, Thervet E, Page B, Percheron A, Noel L, Kreis H. Hydroxyethylstarch and osmotic-nephrosis-like lesions in kidney transplantation. Lancet. 1993;342:238-239.

35. Cittanova ML, Leblanc I, Legendre C, Mouquet C, Riou B, Coriat P. Effect of hydroxyethyl starch in brain-dead kidney donors on renal function in kidney-transplant recipients. Lancet. 1996;348:1620-1622.

36. Deman A, Peeters P, Sennesael J. Hydroxyethyl starch does not impair immediate renal function in kidney transplant recipients: a retrospective, multicentre analysis. Nephrol Dial Transplant. 1999;14:1517-1520.

37. Kumle B, Boldt J, Piper S, Schmidt C, Suttner S, Salopek S. The influence of different intravascular volume replacement regimens on renal function in the elderly. Anesth Analg. 1999;89:1124-1130.

38. Dehne M, Muhling J, Sablotzki A, Dehne K, Sucke N, Hempelmann G. Hydroxyethyl starch (HES) does not directly affect renal function in patients with no prior renal impairment. J Clin Anesth. 2001;13: 103-111.

39. Boldt J, Brosch C, Röhm K, Papsdorf M, Mengistu A. Comparison of the effects of gelatin and a modern hydroxyethyl starch solution on renal function and inflammatory response in elderly cardiac surgery patients Br J Anaesth. 2008;100:457-464. 
40. Boldt J, Brosch C, Röhm K, Lehmann A, Mengistu A, Suttner S. Is albumin administration in hypoalbuminemic elderly cardiac surgery patients of benefit with regard to inflammation, endothelial activation, and long-term kidney function? Anesth Analg. 2008;107:1496-1503.

41. Jungheinrich C, Scharpf R, Wargenau M, Bepperling F, Baron JF. The pharmacokinetics and tolerability of an intravenous infusion of the new hydroxyethyl starch 130/0.4 $(6 \%, 500 \mathrm{ml})$ in mild-to-severe renal impairment. Anesth Analg. 2002;95:544-551.

42. Sakr Y, Payen D, Reinhart K, et al. Effects of hydroxyethyl starch administration on renal function in critically ill patients. Br J Anaesth. 2007;98:216-224

43. Boldt J, Brosch C, Ducke M, Papsdorf M, Lehmann A. Influence of volume therapy with a modern hydroxyethylstarch preparation on kidney function in cardiac surgery patients with compromised renal function: a comparison with human albumin. Crit Care Med. 2007; 35:2740-2746.

44. Fenger-Eriksen C, Rasmussen CH, Jensen TK, et al. Renal effects of hypotensive anaesthesia in combination with acute normovolaemic haemodilution with hydroxyethyl starch 130/0.4 or isotonic saline. Acta Anaesthesiol Scand. 2005;49:969-974.

45. Godet G, Lehat JJ, Janvier G, Steib A, de Castro V, Coriat P. Safety of HES 130/0.4 (Voluven ${ }^{\circledR}$ ) in patients with preoperative renal dysfunction undergong abdominal aortic surgery: A prospective, randomized, controlled, parallel-group multicentre trial. Eur J Anaesthesiol. 2008; 25:986-994.

46. Boldt J, Suttner S, Brosch C, Lehmann A, Röhm K, Mengistu A. The influence of a balanced volume replacement concept on inflammation, endothelial activation, and kidney integrity in elderly cardiac surgery patients. Intensive Care Med. 2009;35:462-470.

47. Sümpelmann R, Kretz FJ, Gäbler R, et al. Hydroxyethyl starch 130/0.42/6:1 for perioperative plasma volume replacement in children: preliminary results of a European Prospective Multicenter Observational Postauthorization Safety Study (PASS). Paediatr Anaesth. 2008; 18:929-933.

48. Schabinski F, Oishi J, Tuche F, et al. Effects of a predominantly hydroxyethyl starch (HES)-based and a predominantly non HES-based fluid therapy on renal function in surgical ICU patients. Intensive Care Med. 2009;35:1539-1547.

49. Roberts I, Alderson P, Bunn F, Chinnock P, Ker K, Schierhout G. Colloid versus crystalloids for fluid resuscitation in critically ill patients. Cochrane Database Syst Rev. 2007;4:CD000567.

50. Sibbald WJ, Driedger AA, Wells GA, Myers ML, Lefcoe M. The shortterm effects of increasing plasma colloid osmotic pressure in patients with non-cardiac pulmonary edema. Surgery. 1983;93:620-636.

51. Finch JS, Reid C, Bandy K, Fickle D. Compared effects of selected colloids on extravascular lung water in dogs after oleic acid-induced lung injury and severe hemorrhage. Crit Care Med. 1983;11:267-270.

52. Pearl RG, Halperin BD, Mihm FG, Rosenthal MH. Pulmonary effects of crystalloid and colloid resuscitation from hemorrhagic shock in the presence of oleic-induced pulmonary capillary injury in the dog. Anesthesiology. 1988;68:12-20.

53. Skillman JJ, Restall S, Salzman EW. Randomized trial of albumin vs electrolyte solutions during abdominal aortic operations. Surgery. 1975; 78:291-303

54. Boutros AR, Ruess R, Olson L, Hoyt JL, Baker WH. Comparison of hemodynamic, pulmonary, and renal effects of use of three types of fluid after major surgical procedures on the abdominal aorta. Crit Care Med. 1979;7:9-13.

55. Virgilio RW, Rice CL, Smith DE, et al. Crystalloid vs colloid resuscitation: is one better? Surgery. 1979;85:129-139.

56. Shires GT, Peitzman AB, Albert SA, et al. Response of extravascular lung water to intraoperative fluids. Ann Surg. 1983;197: 515-519.

57. Gallagher JD, Moore RA, Kerns D, et al. Effects of colloid or crystalloid administration on pulmonary extravascular lung water in the postoperative period after coronary bypass grafting. Anesth Analg. 1985;64: $753-758$.
58. Karanko MS, Klossner JA, Laaksonen VO. Restoration of volume by crystalloid versus colloid after coronary bypass: hemodynamics, lung water, oxygenation, and outcome. Crit Care Med. 1987;15:559-566.

59. London MJ, Ho JS, Triedman JK, et al. A randomized clinical tria of $10 \%$ pentastarch (low molecular weight hydroxyethyl starch) versus $5 \%$ albumin for plasma volume expansion after cardiac operations. J Thorac Cardiovasc Surg. 1989;97:785-797.

60. Tølløfsrud S, Svennevig JL, Breivik H, et al. Fluid balance and pulmonary functions during and after coronary artery bypass surgery: Ringer's acetate compared with dextran, polygeline, or albumin. Acta Anaesthesiol Scand. 1995;39:671-677.

61. Raijmakers PGHM, Groeneveld ABJ, Schneider AJ, et al. Transvascular transport of ${ }^{67} \mathrm{Ga}$ in the lungs after cardiopulmonary bypass surgery. Chest. 1993;104:1825-1832.

62. Raijmakers PGHM, Groeneveld ABJ, Rauwerda JA, et al. Transient increase in interleukin- 8 and pulmonary microvascular permeability following aortic surgery. Am J Respir Crit Care Med. 1995;151: 698-705.

63. Groeneveld ABJ, Raijmakers PGHM. The ${ }^{67}$ Gallium-transferrin pulmonary leak index in patients at risk for the acute respiratory distress syndrome. Crit Care Med. 1998;26:685-691.

64. Pararajasingam R, Nicholson ML, Bell PRF, Sayers RD. Noncardiogenic pulmonary oedema in vascular surgery. Eur JVasc Endovasc Surg. 1999;17:93-105.

65. Ng CSH, Wan S, Yim APC, Arifi AA. Pulmonary dysfunction after cardiac surgery. Chest. 2002;121:1269-1277.

66. Byrick RJ, Kay JC, Noble WH. Extravascular lung water accumulation in patients following coronary artery surgery. Can Anaesth Soc J. 1977;24:332-345.

67. Sivak ED, Starr NJ, Graves JW, Cosgrove DM, Borsh J, Estafanous GE. Extravascular lung water values in patients undergoing coronary artery bypass surgery. Crit Care Med. 1982;10:593-596.

68. Lumb PD. A comparison between $25 \%$ albumin and $6 \%$ hydroxyethyl starch solutions on lung water accumulation during and immediately after cardiopulmonary bypass. Ann Surg. 1987;26:210-213.

69. Wahba A, Sendtner E, Strotzer M, Wild K, Birnbaum DE. Fluid therapy with Ringer's solution versus Haemacel following coronary artery bypass surgery. Acta Anaesthesiol Scand. 1996;40:1227-1233.

70. Verheij J, van Lingen A, Raijmakers PG, et al. Effect of fluid loading with saline or colloids on pulmonary permeability, oedema and lung injury score after cardiac and major vascular surgery. Br J Anaesth. 2006;96:21-30.

71. Weil MH, Henning RJ. New concepts in the diagnosis and fluid treatment of circulatory shock. Thirteenth Annual Becton, Dickinson and Company Oscar Schwidetsky Memorial Lecture. Anesth Analg. 1979;58:124-132.

72. Kuntz C, Kienle P, Schmeding M, Benner A, Autschbach F, Schwalbach P. Comparison of laparoscopic versus conventional technique in colonic and liver resection in a tumor-bearing small animal model. Surg Endosc. 2002;16:1175-1181.

73. Levy MM, Dellinger RP, Townsend SR, et al. (on behalf of the Surviving Sepsis Campaign). The Surviving Sepsis Campaign: Results of an international guideline based performance improvement program targeting severe sepsis. Critical Care Medicine. 2010;38:367-374.

74. Meissner M, Tschaikowsky K, Hutzler A, Schlick C, Schüttler J. Post-operative plasma concentrations of prop-calcitonin after different types of surgery. Intensive Care Med. 1998;24:680-684.

75. Rink L, Cakman I, Kirchner H. Altered cytokine production in the elderly. Mech Ageing Dev. 1998;102:199-209.

76. Lang K, Suttner S, Boldt J, Kumle B, Nagel D. Volume replacement with HES $130 / 0.4$ may reduce the inflammatory response in patients undergoing major abdominal surgery. Can J Anaesth. 2003;50: 1009-1016.

77. Boldt J, Schölhorn T, Mayer J, Piper S, Suttner S. The value of an albumin-based intravascular volume replacement strategy in elderly patients undergoing major abdominal surgery. Anesth Analg. 2006;103: 191-199. 
78. Collis RE, Collins PW, Gutteridge CN, et al. The effect of hydroxyethyl starch and other plasma volume substitutes on endothelial cell activation: an in vitro study. Intensive Care Med. 1994;20:37-41.

79. Volta CA, Alvis V, Campi M, et al. Influence of different strategies of volume replacement on the activity of matrix metalloproteinases: an in vitro and in vivo study. Anesthesiology. 2007;106:85-91.
80. Dieterich H-J, Weissmüller T, Rosenberger P, Eltzschig HK. Effect of hydroxyethyl starch on vascular leak syndrome and neutrophil accumulation during hypoxia. Crit Care Med. 2006;34:1775-1782.

81. Nohé B, Johannes T, Reutershan J, et al. Synthetic colloids attenuate leukocyte-endothelial interactions by inhibition of integrin function. Anesthesiology. 2005;103:759-767.

\section{Publish your work in this journal}

The International Journal of General Medicine is an international, peer-reviewed open-access journal that focuses on general and internal medicine, pathogenesis, epidemiology, diagnosis, monitoring and treatment protocols. The journal is characterized by the rapid reporting of reviews, original research and clinical studies across all disease areas.
A key focus is the elucidation of disease processes and management protocols resulting in improved outcomes for the patient. The manuscript management system is completely online and includes a very quick and fair peer-review system. Visit http://www.dovepress.com/ testimonials.php to read real quotes from published authors.

Submit your manuscript here: http://www.dovepress.com/international-journal-of-general-medicine-journal 